\title{
AMAR E SERVIR NO SUL DA AMÉRICA: origem e articulação dos centros sociais jesuítas
}

\author{
Iraneidson Santos Costa*
}

\begin{abstract}
Desde a Carta de Inácio de Loyola aos Padres e Irmãos de Pádua, de 1547, o Apostolado Social tem se constituído numa das dimensões centrais do carisma da Companhia de Jesus. Tal opção, no entanto, ganhou um relevo maior por ocasião da criação dos chamados Centros de Investigação e Ação Social (CIAS) em diversos países sul-americanos, entre 1950 e 1970. Apoiados em documentação oriunda de diversos arquivos da Companhia de Jesus no Brasil, Itália, México e Paraguai, discutiremos a origem e articulação dos CIAS sul-americanos, inicialmente por intermédio do Secretariado Interamericano de Ação Social (SIAS), logo depois pelo Conselho Latino-Americano dos CIAS (CLACIAS), inserindo-os num contexto fortemente marcado por polarizações ideológicas e políticas. Ao longo do artigo, procuraremos demonstrar a hipótese central de nossa investigação: a trajetória dos CIAS está marcada pela tensão permanente entre duas forças contrapostas: (a) o compromisso com a justiça social e (b) a luta contra o comunismo.

Palavras-chave: Companhia de Jesus. CIAS. Justiça social. Cristianismo de Libertação. América do Sul.
\end{abstract}

\section{INTRODUÇÃO}

Em 7 de outubro de 1970, cerca de trinta homens da Polícia do Exército invadiram a sede do Instituto Brasileiro de Desenvolvimento (Ibrades), no Rio de Janeiro, mantiveram sob custódia, durante todo o dia, dezenas de alunos e professores, inclusive seu diretor, Pedro Belisário Velloso, além do reitor da Pontifícia Universidade Católica do Rio de Janeiro (PUC-Rio), Ormindo Viveiros de Castro, e detiveram quatro alunos, membros da Juventude Operária Católica (JOC), os quais levaram dois meses na cadeia (em setembro, já haviam sido presos no mesmo Ibrades um padre e uma assistente da JOC, Irany Cardoso, que estava grávida e terminou dando à luz na cadeia). Alertado acerca do ocorrido, o secretário-geral da Conferência Nacional dos Bispos do Brasil (CNBB), dom Aloísio Lorscheider, dirigiu-se à entidade e foi igualmente retido. A alegação do Exército para a invasão era de que o Ibrades se

* Universidade Federal da Bahia - UFBA. Faculdade de Filosofia e Ciências Humanas - FFCH. Departamento de História e do Programa de Pós-Graduação em História. Rua: Professor Aristides Novis, n. 197, Federação.

Cep: 40210630. Salvador - Bahia - Brasil. icosta@ufba.br constituía na célula mater da subversão católica no Brasil (Serbin, 2001).

No ano seguinte, Federico Aguiló, José Pratts e Pedro Negre foram presos e deportados da Bolívia por participar de uma greve de fome de denúncia da tortura e do ocultamento de cadáveres de guerrilheiros ocorridos ao longo do governo do general Alfredo Ovando. No início de 1972, o ditador paraguaio Alfredo Stroessner, no poder desde meados da década de 1950, ordenou a expulsão de Vicente Barrero e José Luís Caravias, assessores das Ligas Agrárias Católicas (LAC), o mais contundente movimento de contestação ao regime (Carter, 1991, p. 82-88).

Em abril daquele mesmo ano, em plena crise do governo de Salvador Allende, ocorreu, em Santiago, no Chile, o Primeiro Encontro dos Cristãos pelo Socialismo (CpS), grupo formado por cerca de duzentos sacerdotes, cujo documento final defendeu a participação ativa dos cristãos na construção do socialismo, sem maiores restrições. O secretário geral, Gonzalo Arroyo, era vice-diretor do Centro para o Desenvolvimento Econômico da América Latina (Desal). A revista Mensaje, publicada pelo 
também chileno Centro Bellarmino, apoiou reiteradamente o $\mathrm{CpS}$, defendendo a luta de classes como compromisso cristão (Primeiro Encontro Latino-Americano de Cristãos para o Socialismo, 1973).

Três anos depois, em 1975, o governo civil-militar uruguaio decretou o fechamento do Centro Pedro Fabro, prendeu seu diretor, Juan Luís Segundo, invadiu a sede da entidade e recolheu todos os exemplares da revista Perspectivas de Diálogo, levando-os a um local desconhecido para serem queimados (Segundo, 1998, p. 48-56). No mesmo ano, em Mendoza, na Argentina, uma bomba explodiu enquanto o padre José Maria Llorens, mais conhecido como Macuca, rezava missa na capela do bairro popular de San Martín, no qual vivia há muitos anos e iniciara a organização dos "Campamentos Universitarios de Trabajo", CUT (Klaiber, 2007, p. 328).

Por fim, em outubro de 1978, Cláudio Perani, coordenador do Centro de Estudos e Ação Social (CEAS) e assessor para Assuntos Sociais do arcebispo de Salvador, cardeal Avelar Brandão Vilela, ficou detido no Aeroporto de Salvador por cinco horas, sob risco de ser extraditado de volta à Itália, de onde regressara após estadia de um mês, ao que tudo indica em razão de seu nome constar de uma lista de estrangeiros proibidos de entrar no país. - Somente a intervenção pessoal e imediata do : @ tiça, Armando Falcão, evitou a deportação. Praticamente um ano depois, em setembro de 1979, outro integrante do CEAS, e igualmen\& te estrangeiro, seria o novo alvo da repressão: 될 nascido em Salamanca, mas já com vinte anos \& de residência no Brasil, Manuel Andrés Mato ơ retornava de um Encontro sobre Trabalho, Fé $\dot{s}$ e Justiça realizado no Peru, quando foi surpreendido pela existência de um processo de expulsão movido pela Polícia Federal. Uma vez mais, a interferência de dom Avelar Vilela foi decisiva para impedir o desterro (Costa, 2011, p. 157-159).

\section{O APOSTOLADO SOCIAL JESUÍTICO}

Todos os sujeitos acima citados (o brasileiro Pedro Velloso, o paraguaio Vicente Barrero, o chileno Gonzalo Arroyo, o urugaio Juan Luís Segundo, o argentino José Maria Llorens, o italiano Cláudio Perani e os espanhóis José Luís Caravias, Andrés Mato, Federico Aguiló, José Pratts e Pedro Negre) eram padres jesuítas, e as respectivas entidades às quais estavam vinculados (Ibrades, Centro Bellarmino, Centro Pedro Fabro e CEAS) são Centros de Investigação e Ação Social (CIAS), cuja atuação e intercâmbio, na segunda metade do século XX, constituem o objeto deste artigo.

Não são pequenos os desafios. O primeiro deles certamente é a invisibilidade dos CIAS, cuja ação foi preferencialmente discreta, sem querer explicitar qualquer protagonismo, mesmo quando exercendo considerável influência na orientação de certos processos. Isso se traduziu na própria estruturação física dos centros, cujas sedes, via de regra, passam despercebidas nas grandes cidades, situadas em ruas transversais, de pouco movimento, sem indicação do nome na fachada etc. Essa característica foi certamente acentuada no caso dos CIAS sul-americanos, na medida em que seu período de surgimento e maturação (décadas de 1950 e 1960) coincidiu com a implantação de regimes autoritários, quando não abertamente ditatoriais, em boa parte do continente.

Agrega-se a isso a dispersão da documentação. Sediado em Roma e primorosamente organizado, o Archivum Historicum Societatis Iesu (AHSI) guarda uma parcela diminuta da documentação dos CIAS, a qual se encontra depositada, em grande medida, na própria sede do Secretariado de Justiça Social (SJS), igualmente localizado na capital italiana. No entanto, em que pese a riqueza do acervo, sua consulta não é das mais fáceis, já que o SJS, órgão responsável pela coordenação do apostolado social da Companhia de Jesus no mundo, não possui um centro de documentação. Assim, não resta al- 
ternativa senão pesquisar a documentação disponível em cada CIAS sul-americano.

Desse modo, não chega a surpreender a escassa produção historiográfica acerca dos CIAS na América Latina, em geral, e na América do Sul, em particular. Os trabalhos de Ignacio Riera (1968), Paulo Meneses (1994) e Michael Czerny e Paolo Foglizzo (2000) esboçam análises preliminares desses Centros, evidentemente circunscritas aos limites de breves artigos. O opúsculo do jesuíta paraguaio Ricardo Antoncich (s. d.) consiste numa rica descrição da história do apostolado social da Companhia de Jesus, no interior do qual se destacam os CIAS. Por fim, a obra de fôlego de Jeffrey Klaiber, historiador norte-americano radicado no Peru e recentemente falecido, Los Jesuitas en América Latina, 1549-2000, tem o mérito de apresentar uma visão de conjunto da ação social da Companhia de Jesus, ainda que não traga uma análise aprofundada do desempenho dos referidos Centros de Investigação e Ação Social.

Um bom ponto de partida para a delimitação do nosso objeto e, consequentemente, da problemática a ser enfrentada ao longo destas páginas, parece ser a própria definição consagrada nos Estatutos dos CIAS, promulgados em dezembro de 1966:

O objetivo fundamental dos CIAS é (em consonância com o objetivo fundamental do Apostolado Social) a transformação da mentalidade e das estruturas sociais num sentido de justiça social, prioritariamente no setor de promoção popular, a fim de tornar possíveis uma maior dedicação, participação e responsabilidade em todos os níveis da vida humana ${ }^{1}$

O surgimento desses Centros se deu num contexto histórico bastante singular, uma verdadeira encruzilhada de conjunturas: (1) da história social e política latino-americana, profundamente influenciada pelo triunfo (1959) e posterior orientação socialista (1961-1962) da Revolução Cubana; (2) da trajetória da Igreja Católica mundial, sob o impacto do recém-

${ }^{1}$ Estatutos dos CIAS, Roma, 12 de dezembro de 1966, p. 1 tradução nossa. Arquivo do Secretariado de Justiça Social (ASJS), Roma, Caixa CIAS. concluído Concílio Vaticano II (1962-1965), cuja opção preferencial pelos pobres se faria sentir de maneira mais contundente justamente na América Latina, sobretudo após a realização da II ${ }^{a}$ Conferência Geral do Episcopado Latino-Americano (Celam), ocorrida na cidade colombiana de Medellín, em 1968, e o posterior florescimento da Teologia da Libertação; e, por último, mas nem por isso menos importante, (3) do percurso da própria Companhia de Jesus a partir de meados da década de 1970, particularmente após a eleição do Padre Geral Pedro Arrupe (em maio de 1965), responsável por conduzir essa ordem religiosa ao compromisso explícito em prol da justiça social.

Como explicar essa sensível inflexão ao interior do cristianismo, rompendo com uma longa tradição política conservadora e regressiva? E como essa nova tendência, denominada por muitos de Cristianismo de Libertação, pôde se desenvolver e amadurecer num momento histórico determinado do continente latino-americano? De acordo com Michael Löwy (2000), um dos mais fecundos estudiosos da conexão entre Religião e Política no continente latino-americano, tal "virada" resultou de uma combinação de mudanças internas e externas à Igreja Católica ocorridas na década de 1950 e desenvolvidas a partir da periferia e na direção do centro da instituição. Para ele, foi "a convergência desses conjuntos muito distintos de mudanças que criou as condições que possibilitaram a emergência da Igreja dos Pobres" (Löwy, 2000, p. 70).

Cumpre esclarecer, para entender sua argumentação, que as mudanças internas incluíam as inovadoras correntes teológicas (principalmente francesas e alemãs), as novas formas de cristianismo social (como o movimento dos padres operários), o pontificado de João XXIII (1958-1963) e o já mencionado Concílio Vaticano II; por sua vez, por externas, este autor tem em mente, sobretudo, o processo de industrialização do continente, sob a hegemonia do capital multinacional, o êxodo rural e a consolidação de uma nova classe trabalhadora urbana, 
bem como a Revolução Cubana, de 1959.

Com efeito, o fenômeno religioso constitui um terreno de grande interesse para os estudos históricos, sobretudo quando investigado em conexão com os movimentos sociais, de maneira especial na América Latina. Nas últimas quatro décadas do século XX, a trajetória das classes populares latino-americanas esteve marcada, em grande medida, por movimentos de caráter religioso, sobretudo no campo cristão, tanto católico como protestante. É inegável a importância assumida pela chamada Igreja Progressista, o que culminou na estruturação das Teologias da Libertação e da Terra e numa intensa atuação das Comunidades Eclesiais de Base (CEBs) e das Pastorais Sociais. Menos estudada, mas nem por isso menos decisiva, foi a ação, nesse mesmo período, dos CIAS fundados pela Companhia de Jesus em todo o continente a partir da década de 1950.

A implantação de ditaduras militares e (ou) civis-militares no continente latino-americano, sobretudo em sua porção meridional, marcou indelével e tragicamente a trajetória dessa porção do mundo na segunda metade do século passado. O restabelecimento da normalidade democrática, em alguns casos há pouco mais de duas décadas, não significou, todavia, o esquecimento desse processo, antes tem permitido sua avaliação mais criteriosa. Dessa - maneira, o debate em torno dos objetivos, con-

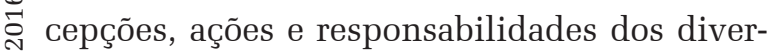
$œ$ sos grupos sociais envolvidos continua atual I. na agenda política dessas nações, tanto mais ¿. que as pesquisas vêm demonstrando que não §̊ se tratou de um fenômeno isolado, e sim de 될 uma associação íntima entre grupos militares $\therefore$ e civis desses países, com o envolvimento mais oे ou menos direto dos Estados Unidos.

As ditaduras de Paraguai (1954-1989), Brasil (1964-1985), Bolívia (1964-1982), Uruguai (1973-1985), Chile (1973-1990) e Argentina (1976-1983) se retroalimentaram mediante a chamada Operação Condor, aliança políticomilitar criada com o propósito de unificar a ação repressora no Cone Sul (Dinger, 2005). A atuação conjunta não foi, contudo, uma exclusividade das forças repressivas, pois também esteve presente entre as diversas organizações e movimentos sociais opositores a tais regimes autoritários, aspecto que não tem merecido a devida atenção dos estudos históricos mais recentes. Neste artigo, investigaremos justamente a articulação de uma rede de combate às ditaduras do Cone Sul por parte da esquerda católica sul-americana na segunda metade do século XX, inspirados pela ponderação formulada por Paulo Meneses (1994, p. 277-278):

\begin{abstract}
Quando se fizer uma avaliação de conjunto dos trabalhos do CIAS, é preciso que não se esqueça do campo minado em que tiveram de trabalhar em quase toda a parte: ditaduras militares, guerrilhas etc. As atividades pastorais e educativas nem de longe suscitaram a desconfiança que um trabalho de conscientização e de ação social produz nesses regimes militares. A luta em defesa dos direitos humanos é mais perigosa onde é mais necessária.
\end{abstract}

Desde a Carta de Inácio de Loyola aos Padres e Irmãos de Pádua (de 1547), não à toa conhecida como a Carta da Pobreza (Loyola, 1991), até o documento sobre o Neoliberalismo na América Latina (1996), o Apostolado Social tem se confirmado como uma das dimensões centrais do carisma inaciano, de modo que a constituição e a atuação dos CIAS latino-americanos, em geral, e sul-americanos, em particular, parece-nos representar um fato notável não apenas na história da Companhia de Jesus no mundo (vez que em nenhum outro lugar assumiram tal projeção), como no próprio percurso da Igreja Católica nas últimas quatro décadas do século XX.

Mas é preciso recuar ao final do século XIX para compreender, de maneira adequada, tal mudança. A tradição nos ensina que a Doutrina Social da Igreja (DSI) teve seu marco fundacional em 1891, quando o papa Leão XIII lançou a encíclica Rerum Novarum, a primeira dedicada integralmente à chamada questão social. Nela, instigava todos os cristãos a enfrentar os problemas sociais não apenas com caridade, virtude evangélica milenar, como 
também mediante a transformação da sociedade. Não cabe aqui discutir o conteúdo dessa transformação, seus limites óbvios, o próprio caráter defensivo da proposta: interessa-nos, de momento, ressaltar o ponto de inflexão no pensamento social da Igreja Católica e na sua ação junto aos pobres.

Ao reconhecer, nas instituições e estruturas sociais, a causa das condições de vida injustas e miseráveis da classe operária, a Igreja Católica começou a encontrar sua identidade no mundo moderno: evangelizar não somente as pessoas ou comunidades, senão a própria sociedade industrial. Como afirmam dois estudiosos desse processo, "sem negar a necessidade das obras de misericórdia, a nova missão era essencialmente social. É possível dizer que, com este descobrimento, nascia o apostolado social no sentido moderno da palavra" (Czerny; Foglizzo, 2000, p. 7, tradução nossa).

A Companhia de Jesus não tardaria em repercutir esse influxo pontifício, ainda que de maneira tímida: já no ano seguinte, a Congregação Geral XXIV trazia um solitário parágrafo onde estimulava a criação de associações que ajudassem os trabalhadores e os pobres a se formar, crescer em espírito e empreender "todo tipo de obras de piedade e caridade". ${ }^{2}$ Apesar de a própria Rerum Novarum ter tido a decisiva participação de jesuítas em sua elaboração (Camacho, 1995, p. 53-58), nesse momento, a Companhia de Jesus se encontrava um passo atrás do Vaticano no que tange à doutrina social. Ao invés da admissão da necessidade de transformação das estruturas sociais, o documento reforçava a via das obras de caridade, sem diferenciá-las da ação social, bem ao estilo da Carta da Pobreza.

Quase meio século depois, a realidade seria completamente diferente. Em 1938,

${ }^{2}$ A Congregação Geral é uma espécie de assembleia geral da Companhia de Jesus, composta por representantes eleitos das diversas Províncias da Ordem em número proporcional à sua quantidade de jesuítas. Reunida pela primeira vez em 1558, consiste não apenas no colégio eleitoral para a escolha do Prepósito Geral, como também no seu corpo legislativo, responsável pela aprovação das Normas Complementares das Constituições, dos Decretos e demais documentos. a Congregação General XXVIII declarou que o trabalho do apostolado social da Companhia de Jesus se adequava perfeitamente ao ensinamento das encíclicas Rerum Novarum e Quadragesimo Anno, e, o que foi mais relevante, deveria se promover no mundo inteiro, de maneira urgente, a fundação de centros de investigação e ação social, destinando para trabalhar neles jesuítas de dedicação total e formação acadêmica em economia ou ciências sociais. Um passo à frente da Cúria Romana, portanto, na medida em que superava o âmbito das intenções e exortações, apresentando uma proposta institucional concreta para a formulação e encaminhamento das desejadas mudanças sociais, os referidos centros.

É significativa a menção à encíclica Quadragesimo Anno, publicada em 1931, já no papado de Pio XI (1922-1939). Redigida por outro grupo de jesuítas, entre os quais se destacavam Gustave Desbuquois, da Action Populaire de Paris, e Oswald von Nell-Breuning, de Frankfurt, propugnava uma alternativa ao liberalismo capitalista e ao coletivismo socialista: o corporativismo. Ao conceber a sociedade como um compósito de corporações profissionais ao interior da qual as classes sociais deveriam se organizar, o corporativismo pretendia solucionar o problema da desigualdade e da pobreza, na medida em que assegurava um espaço efetivo de representação e reivindicação para todos os grupos sociais, sem recorrer à luta de classes, já que a relação entre as corporações seria regida pelos princípios do respeito e da cooperação mútuos.

Tal reorientação no pensamento social da Companhia de Jesus não se deveu a um milagre caído dos céus. Desde o final do século XIX, os jesuítas haviam iniciado um estudo sistemático do socialismo científico. Em 1882, um jesuíta italiano, Valentino Steccanella, publicou um livro chamado Del Communismo. Em 1890, um ano antes da encíclica fundadora, Matteo Liberatore (o mesmo que havia participado de sua redação) publicou o artigo Ferdinand Lassale e Carlos Marx em La Civiltà 
Católica, a mais antiga revista da Companhia (criada em 1850) e uma das mais prestigiosas da Europa. Entre 1897 e 1898, apareceram, na mesma revista, outros artigos de refutação do marxismo, sob o título de Le rivendicazioni operaie e il socialismo scientifico, nos quais Marx, após ser apresentado como um erudito, profundo conhecedor da literatura econômica inglesa, era anatematizado por seus sofismas, tendo assumido "uma dialética hegeliana ao mesmo tempo pérfida e flexível" (apud Calvez, 2001, p. 1457, tradução nossa).

A partir da década de 1940, multiplicaram-se os artigos em La Civiltà Católica sobre as concepções de Marx: em 1944, sairia Il Comunismo, de Angelo Brucculeri; três anos depois, seria a vez de La dottrina marxista, obra coletiva organizada por Riccardo Lombardi, Ulisse Floridi e Giuseppe de la Rosa, entre outros. Na França e na Alemanha, essa produção foi um pouco mais tardia, ainda que mais robusta intelectualmente. Ao longo dos anos 1940, os jesuítas publicaram alguns artigos sobre o marxismo em diversos periódicos franceses. Pierre Bigo, colega de Gustave Desbuquois em Action Populaire e, como veremos adiante, figura central na constituição dos CIAS sul-americanos, escreveu, em 1947, um texto em Travaux de Action Populaire chamado Débat sur le marxisme. Henry Chambre, outro jesuíta francês, produziu, nessa década, pelo menos seis trabalhos analisando a relação entre o $₫$ marxismo e o comunismo.

Entretanto, seria somente na década seguinte que a leitura jesuítica de Marx experimentaria seu primeiro grande florescimento, com a publicação de obras fundamentais: Der dialektische Materialismus: seine Geschichte und sein System in der Sowjetunion (1952), de Gustav Andreas Wetter; Marxisme et Humanisme: introduction à l'oeuvre économique de Karl Marx (1953), do já citado Pierre Bigo; Le marxisme en Union Soviétique: idéologie et institutions leur évolution de 1917 a nos jours (1955) e De Karl Marx a Mao Tsé-Tung: introduction critique au Marxisme-Léninisme (1959), ambos de Henri Chambre, e, por fim, Marxisme et liberté (1956) e La Pensée de Karl Marx (1956), de Jean-Yves Calvez (Cf. Costa, 2010). O século $\mathrm{XX}$ veria não apenas o aprofundamento desses estudos como também a criação dos primeiros centros sociais da Companhia de Jesus, como podemos verificar no Quadro 1.

A primeira observação se refere à sua precocidade, já que Action Populaire antecipou, em três décadas, as recomendações da Congregação Geral XXVIII. Fundada em 1903 em Reims, e logo depois transferida para Vanves, nos arredores de Paris, abrigou, nas décadas seguintes, uma equipe formada por cerca de uma dúzia de jesuítas, sob a regência de um de seus fundadores e diretor desde 1905, o padre Gustave Desbuquois. Action Populaire converteu-se num dos principais focos de irradiação do catolicismo social na França, concentrando sua atuação na formação e organização da juventude operária, numa indisfarçável competição com o crescente movimento socialista. Não apenas em sua sede parisiense como também na filial de Lyon, dirigida por Joseph Folliet, esse centro exerceu uma influência considerável sobre o sindicalismo operário e patronal católico, movimentos de juventude e cooperativistas, através das conferências e cursos ministrados, das Semanas Sociais organizadas anualmente e dos periódicos publicados, a exemplo dos célebres Folhetos Amarelos (Droulers, 1981). Os CIAS latino-americanos teriam nela uma de suas inequívocas matrizes.

Outra constatação diz respeito ao amplo predomínio do eixo Europa-América do Norte, que responde por nada menos do que dez dos doze centros sociais fundados pela Companhia de Jesus na primeira metade do século passado. E mesmo as duas honrosas exceções precisam ser matizadas: o Institute of Social Order fundado por Walter Hogan nas Filipinas, em 1946, é bem mais uma filial do ISO original norte-americano. Por sua vez, Hogar de Cristo, cuja vitalidade se mantém até hoje no cenário da assistência social chilena, deve ser entendido antes como resultado do esforço individual 
Quadro 1 - Centros Sociais da Companhia de Jesus na primeira metade do século XX

\begin{tabular}{|c|c|c|c|}
\hline Nome & Ano de fưndação & Sede & Jesuíta(s) fundador(es) \\
\hline Action Populaire $(A P)^{*}$ & 1903 & $\begin{array}{c}\text { França } \\
\text { (Reims; Paris) }\end{array}$ & $\begin{array}{l}\text { Henri-Joseph Leroy } \\
\text { Gustave Desbuquois }\end{array}$ \\
\hline Catholic Social Guild & 1909 & Inglaterra & Charles Plater \\
\hline $\begin{array}{l}\text { École Sociale } \\
\text { Populaire (ESP) ** }\end{array}$ & 1911 & $\begin{array}{c}\text { Canadá } \\
\text { (Montreal) }\end{array}$ & Joseph-Papin Archambault \\
\hline Catholic Workers College & 1921 & Inglaterra & Charles Plater \\
\hline Institut d'Études Sociales (IES) & 1923 & $\begin{array}{l}\text { França } \\
\text { (Paris) }\end{array}$ & $\begin{array}{l}\text { Gustave Desbuquois } \\
\text { Chanoine Verdier }\end{array}$ \\
\hline Fomento Social (FS) & 1926 & $\begin{array}{l}\text { Espanha } \\
\text { (Madri) }\end{array}$ & Sisinio Nevares \\
\hline Catholic Interracial Council & 1934 & $\begin{array}{l}\text { Estados Unidos } \\
\text { (Nova York) }\end{array}$ & John LaFarge \\
\hline Institute of Social Order (ISO) & 1939 & $\begin{array}{c}\text { Estados Unidos } \\
\text { (Nova York, Saint Louis) }\end{array}$ & John Delaney \\
\hline Hogar de Cristo & 1944 & $\begin{array}{c}\text { Chile } \\
\text { (Santiago) }\end{array}$ & Alberto Hurtado \\
\hline Centro Studi Sociali di San Fedele & 1946 & $\begin{array}{l}\text { Itália } \\
\text { (Milão) }\end{array}$ & Giacomo Perico \\
\hline Institute of Social Order (ISO) & 1946 & Filipinas & Walter Hogan \\
\hline Institute of Indus Relations & 1948 & $\begin{array}{l}\text { Estados Unidos } \\
\text { (Nova Orleans) }\end{array}$ & Louis Twomey \\
\hline
\end{tabular}

Fontes: Elaborado pelo Autor

* A partir de 1961, passou a se chamar Centre de Recherche et Action Sociale (CERAS).

** Deu origem, em 1950, ao Institut Social Populaire [ISP).

do seu criador, Alberto Hurtado Cruchaga, ca- berto Hurtado, o único sul-americano dentre nonizado em 2005 pelo papa Benedito XVI, do os pioneiros da ação social jesuíta, teve uma que exatamente de uma iniciativa institucional (Lavín; Holley; Larraín, 2005).

Não há dúvida de que as investigações acerca das causas da injustiça e as ações desenvolvidas por esses centros jesuítas em prol das mudanças sociais contribuíram para o aperfeiçoamento da Doutrina Social da Igreja. Mas foi somente a partir do generalato do belga Jean-Baptiste Janssens (1946-1964) que a Companhia de Jesus adentrou num novo e decisivo momento, com a publicação, em outubro de 1949, da "Instrução sobre o Apostolado Social":

Os mais exímios dentre esses Padres constituam um “Centro de Informação e Ação Social”, se o país não tiver uma organização semelhante; a finalidade seja não tanto dedicar-se às chamadas “obras”, mas, principalmente, ensinar aos outros a doutrina teórica e prática, de modo particular aos sacerdotes, aos leigos cultos e aos mais adiantados dentre os operários, ajudando-os com sua orientação (Janssens, 1991, p. 99).

É interessante ressaltar que padre Alparticipação relevante na elaboração dessa Instrução. Conhecido do jesuíta belga desde a licenciatura em teologia, realizada em Louvain (Bélgica) entre 1931 e 1934, quando o padre Janssens era reitor do Escolasticado (tendo presidido, inclusive, sua banca de defesa), Hurtado haveria de reencontrá-lo, já na condição de recém-eleito Prepósito Geral da Sociedade de Jesus, na viagem que realizou à Europa (1947-1948), quando tiveram pelo menos três encontros. Num deles, ocorrido no início de outubro de 1947, ao conversarem sobre o apostolado social, o agora Geral Jean-Baptiste Janssens, impressionado pela sua descrição e análise do catolicismo social chileno, teria lhe dito: "Quantos dias você vai ficar em Roma? Por que não me sugere algumas ideias para uma carta sobre este tema que pretendo escrever em breve à Companhia? ". ${ }^{3}$ 
A referida carta seria publicada dois anos depois, na forma de Instrução. O tom, inequivocamente elitista, e a proposta, mais doutrinária que prática, haveriam de sofrer significativas alterações no decorrer da estruturação efetiva dos CIAS nos dezessete anos seguintes, como podemos constatar no próprio texto dos Estatutos dos CIAS, anteriormente citado, em que se redirecionou seu objetivo fundamental, no sentido da "transformação da mentalidade e das estruturas sociais num sentido de justiça social”. Contudo, se é verdade que foi apenas no tempo do Geral Pedro Arrupe (1965-1983) que os CIAS assumiram o formato pelos quais haveriam de interferir na vida social e política latino-americana, não se pode desprezar, em absoluto, essa primeira fase de proposição e montagem.

De todo modo, a transformação no conteúdo e na ação dos CIAS não foi um caso de milagre. Antes que uma modificação estatutária, supostamente implantada de cima para baixo, a realidade vivenciada pelos milhares de jesuítas comprometidos com classes populares condicionou a adesão radical desses Centros Sociais à luta pela justiça. Na bela expressão do Geral Peter-Hans Kolvenbach (1983-2008), sucessor de Pedro Arrupe, "foi a América Latina que abriu os olhos dos jesuítas ao amor preferencial pelos pobres e à verdadeira libertação integral do homem" (apud Estudios Centro-Americanos, 1985, p. 56).

\section{AS PRIMEIRAS TENTATIVAS DE ARTICULAÇÃO}

De modo a intensificar, na América Latina, o apostolado social especializado, sobretudo os CIAS, praticamente inexistentes no continente, o padre Jean-Baptiste Janssens nomeou em 1955 um Visitador Social para a região. O título oficial do cargo era Visitador de América Latina de re sociali, o que, segundo as Constituições da Ordem, conferia a essa pessoa a prerrogativa de atuar em nome do Padre
Geral "pelo tempo e com a autoridade que julgar oportuna” (Aixalá, 2001, p. 1748, tradução nossa). Ou seja, com um poder superior ao dos Provinciais e Vice Provinciais, pelo menos na questão social.

O escolhido foi o cubano Manuel Foyaca de la Concha (1905-1994). Filho de asturianos, ainda criança Manuel Foyaca foi para a Espanha, onde ingressou na Companhia de Jesus e se formou em Filosofia e Sociologia. Retornando à ilha apenas em 1940, uma de suas primeiras atribuições foi ensinar História da América e Sociologia no prestigioso (e elitista) Colégio de Belém, localizado em Havana, tendo sido professor, entre outros, de Fidel Castro. ${ }^{4}$ Pela sólida formação intelectual e grande talento organizativo, logo se tornou um dos mais importantes intelectuais católicos do país, ocupando cargos de destaque, como assessor nacional da Ação Católica, editor da revista Justicia Social Cristiana, fundador do movimento Democracia Social Cristã e diretor do Centro Social de Havana, precursor dos CIAS latino-americanos.

Não sabemos precisamente o que teria levado Jean-Baptiste Jannsens a tal decisão, já que a atuação de Foyaca, apesar de intensa, se circunscrevia ao Caribe. É bem provável que a escolha tivesse recaído no amigo chileno, padre Alberto Hurtado, caso ele não tivesse morrido precocemente em 1952, aos 52 anos, vítima de um câncer. Os vínculos pessoais entre o Geral e seu Visitador cubano são ainda matéria de investigação. Tudo indica que eles tenham se conhecido quando Foyaca foi obrigado a se exilar, juntamente com todos seus irmãos religiosos, por conta da dissolução da Companhia de Jesus, decretada pelo governo republicano espanhol em 23 de janeiro de 1932. Parte de sua formação foi feita em Marneffe (perto de Liège, região da Valônia, na Bélgica Meridional), sede do Filosofado e Teologado conjunto das Províncias de Castela e Leão (à qual Foyaca estava adscrito) durante o desterro. Naquela ocasião,

${ }^{4}$ Em 1961, por conta da reforma educacional implementada pelo governo revolucionário, o ensino privado foi estatizado, razão pela qual a Companhia de Jesus transferiu o colégio para Miami (Estados Unidos), onde funciona até hoje. 
Jean-Baptiste Janssen era, como vimos, reitor do Teologado de Louvain, pertencente à outra Província belga (a Setentrional), o que deve ter facilitado a relação entre os dois.

A missão do Visitador consistiu em percorrer todos os países do continente, diagnosticar a situação do apostolado social em cada uma das dezenove Províncias, Vice-Províncias e Missões, identificar e selecionar jovens jesuítas com vocação para a ação social, enviá-los à Europa ou aos Estados Unidos para se especializar nas ciências sociais, políticas ou econômicas e, por fim, incumbi-los de, em retornando a seus países de origem, constituir (ou fortalecer) os CIAS. Numa Instrução publicada provavelmente logo no início do seu mandato, Manuel Foyaca exortou os jesuítas a terem uma solicitude especial para com os grupos sociais (a classe operária e a camponesa) mais vitimados pela ordem social injusta e mais expostos à descristianização sob a ação do comunismo ateu, resumindo em três pontos a ingente tarefa que se colocava para a Companhia de Jesus:

1. É necessário organizar Centros ou Secretarias de ação social, que orientem e impulsionem este apostolado, já que as forças desunidas têm menos eficácia. Secretariados que cooperem entre si em nível nacional e universal [...]. 2. É necessário destinar a este apostolado "padres verdadeiramente aptos". Não padres inúteis, com os quais o Padre Provincial não possa contar para outras coisas... Padres verdadeiramente aptos! Que tenham todo tipo de qualidades requeridas para esta difícil ação. 3. Padres que se entreguem por completo a este ministério. Hoje a ação social não pode ser um passatempo ao qual se dedicam os minutos roubados da sesta... (Foyaca, 1991, p. 119).

Relevada por ora a rudeza do tom, seu desempenho pode ser aferido pela evolução quantitativa dos centros no período, conforme se acompanha no Quadro 2, na página a seguir:

O cenário era bastante alentador, a começar pela abrangência, já que apenas três das dezenove circunscrições latino-americanas não possuíam um CIAS ao final da década de 1960. Mais importante, porém, é a dimensão qualitativa: os cento e vinte e um jesuítas alo- cados nesses centros podem parecer numericamente irrisórios (sobretudo quando comparados aos mais de quatro mil padres, irmãos e noviços espalhados pelos quatro cantos do continente), mas, se considerarmos que eles: (1) estavam seguramente entre os melhores quadros intelectuais da Ordem; (2) não apenas ensinavam como também dirigiam boa parte das mais importantes universidades privadas, a exemplo das PUCs (Pontifícias Universidades Católicas) da Colômbia (a Javeriana), do Equador, do Peru e do Rio de Janeiro (Brasil) e demais universidades católicas, como as da Argentina (tanto a portenha El Salvador quanto a de Córdoba), as Centro-Americanas (com sedes na Guatemala, El Salvador e Nicarágua), do Chile, do Paraguai, do Uruguai (a Dámaso Antonio Larrañaga) e da Venezuela (a Andrés Bello); e (3) eram responsáveis pela publicação de algumas das mais reputadas revistas da época, a exemplo de Cadernos do CEAS e Síntese (Brasil), Christus (México), Estudios Centro-Americanos (El Salvador), Mensaje (Chile), Perspectivas de Diálogo (Uruguai), Revista Javeriana (Colômbia), SIC (Venezuela) e Stromata (Argentina), somos levados a admitir o prestígio social e acadêmico então gozado por esses CIAS $^{5}$.

Para além do êxito evidente do ponto de vista dos resultados, contudo, vale a pena averiguar como se deu esse processo, bem como suas principais repercussões no continente, sobremaneira nos países da América do Sul. Apesar de formalmente residente em Havana, Manuel Foyaca passava mais tempo viajando pelas diversas Províncias. No Brasil, por exemplo, ele fez pelo menos duas visitas: em 1957 e em 19586. Possuímos um relato saboroso de uma delas, ocorrida em maio de 1957, em Itaici (São Paulo), onde a Companhia de Jesus ha-

${ }^{5}$ Para a composição do Quadro 2, utilizamos os dados publicados em Informaciones del Clacias, n. 2. Santiago, jun. 1969. Arquivo dos Jesuítas do Paraguai (AJP), Assunção, Caixa CEPAG-CIAS (1964-1976).

${ }^{6}$ Entrevista com padre Antônio Abreu. São Paulo, 6 de maio de 2015. Aproveito para agradecer não apenas as preciosas informações concedidas pelo padre Abreu como também a divertida e vívida rememoração dos primeiros tempos dos CIAS. 


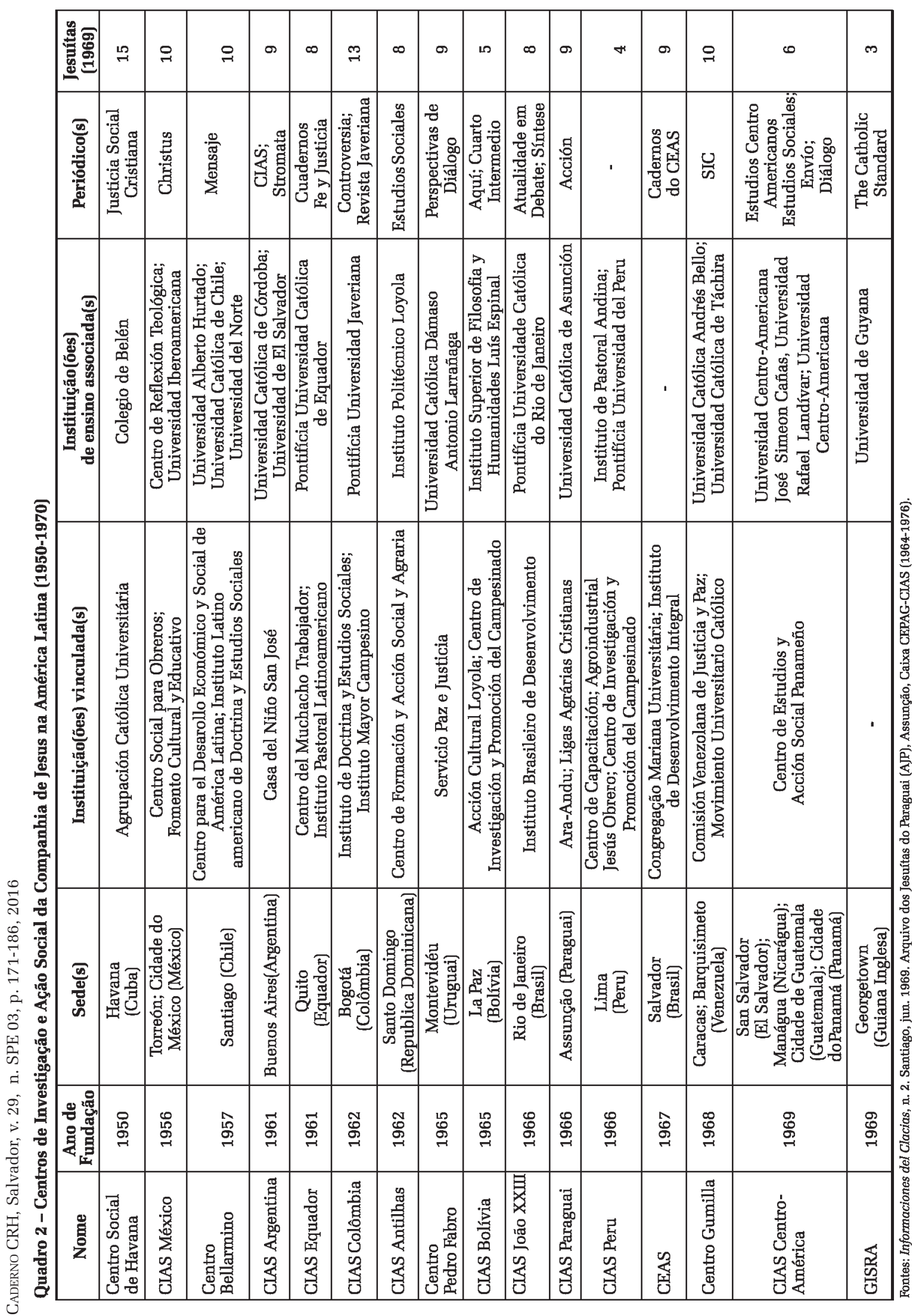


via construído uma imensa Casa de Formação:

O Padre Geral Janssens havia enviado um visitador para animar o trabalho social nas províncias da América Latina. Foi avisado que ele entrevistaria jovens jesuítas voluntários para o trabalho social. Eu, noviço, sonhava com realizar a paixão de meu pai pela dignidade humana, iluminado pela fé de minha mãe no amor de Deus. Conversava com um companheiro, paulistano, advogado e ex-jucista (que depois deixou a Companhia), sobre um serviço novo na PUC-Rio ou na FEI, para formar cristãos a partir da fé para a ação social e política. Então, fui alegrinho e esperançoso falar com o Visitador. Cortou-me rente: "Oigo que Usted es más bien un intelectual. En América Latina solo nos hacen falta hombres de acción. Lo que hay que pensar, los franceses y los belgas ya lo han pensado todo". (Abreu, 2010)

Definitivamente, o trato suave parece não ter feito parte do caráter do jesuíta cubano. Na Argentina, sua intervenção "gerou um mal -estar” (Morello, 2000, p. 51). No Chile, foi considerado un poco simplote por Roger Vekemans, um jesuíta belga (um dos que já pensaram tudo) radicado no país desde 1957 e responsável pela fundação do CIAS local (Beigel, 2011, p. 209).

Por sua vez, outra parcela do tempo do Visitador transcorria na Europa, seja em Roma, na sede da Cúria Geral da Sociedade de Jesus, onde periodicamente eram realizadas reuniões com diretores dos CIAS, seja em encontros com os jovens jesuítas por ele destinados aos estudos especializados, os chamados Congressos Foyaquistas, dos quais nos dá noticia um jesuíta mexicano:

No próximo verão espero ver ao padre Foyaca, pois haverá uma reunião dos jesuítas latino-americanos que estudam Ciências Sociais na Europa, que dirigirá o padre Bigo, de Action Populaire. Terá lugar em Anvers [Antuérpia] de 18 a 25 de agosto. Quero aproveitar a ocasião para propor ao P. Foyaca alguma orientação já mais determinada [...]. As próximas férias passarei em Londres para exercitar o inglês, exceto a semana em que irei a Anvers para a reunião dos "socialistas". Já te contarei mais detalhes quando os tenha. ${ }^{7}$

${ }^{7}$ Carta de Xavier Enríquez para Carlos de la Torre Uribarren. Roma, 26 de abril de 1960, tradução nossa. Arquivo Histórico da Companhia de Jesus no México (AHCJM), Caixa CIAS, Pasta Correspondência de Carlos de la Torre Uribarren.
Além de ratificar a influência dos jesuítas franceses (outros que já pensaram tudo) de Action Populaire na formação dessa segunda geração de jesuítas dos CIAS (a primeira tinha sido responsável por sua fundação e estava trabalhando efetivamente neles), a correspondência do jovem Xavier Enríquez nos chama a atenção para um aspecto crucial no apostolado social: o ideológico. A ironia implícita na qualificação da referida reunião dos jesuítas estudantes remete ao caráter polêmico que o debate ideológico assumia entre os diversos grupos cristãos naquela conjuntura, especialmente os latino-americanos, e que estaria na origem de algumas das crises vivenciadas nas décadas seguintes.

No caso da constituição dos CIAS da América Latina, o tema era particularmente sensível. Nunca é demais lembrar que o Visitador, que já havia sofrido o primeiro exílio na década de 1930 por causa de um governo socialista, estava às vésperas de passar por uma experiência similar, dessa vez mais traumática e duradoura. O desgaste na relação entre a Igreja Católica e o governo revolucionário cubano estava chegando a seu ponto máximo, cujo estopim se deu com o episódio da frustrada tentativa de invasão da Baía dos Porcos, em 17 de abril de 1961. Muitos dos seus líderes eram militantes da Agrupação Católica Universitária (ACU), grupo de leigos católicos fundado em 1926 pelo jesuíta Felipe Rey de Castro como Congregação Mariana (sob o lema Ganar Cuba para Cristo) e, desde, então dirigida por membros da Sociedade de Jesus.

A reação do governo foi rápida: no mês seguinte, cento e trinta e dois sacerdotes e religiosos (chamados de curas falangistas), entre os quais vinte e seis jesuítas, foram expulsos de Cuba, em direção a Vigo (Espanha), a bordo do navio espanhol Covadonga. Restaram apenas quarenta e nove jesuítas na ilha, os quais tiveram de se limitar a trabalhar em paróquias e num Seminário Menor. A princípio, a condição de cubano servia como um atenuante para Manuel Foyaca, já que a deportação priorizou 
os estrangeiros, mas os laços estreitos da ACU com o movimento da Democracia Social Cristã por ele fundada, bem como a crescente restrição da liberdade política, terminaram levando -o ao segundo (e definitivo) exílio: primeiro, na República Dominicana e, a partir de 1967 e até sua morte, em 1994, na Espanha, terra natal dos seus pais e que passou a chamar de sua quando se naturalizou espanhol, ainda em novembro de 1961.

O tema do comunismo passou a galvanizar o apostolado social jesuíta. Em setembro de 1960, numa reunião convocada pelo Geral Janssens com os diretores dos CIAS, em Roma, discutiu-se com Foyaca a situação da América Latina, a consolidação dos CIAS, o impacto da Revolução Cubana nas organizações sociais católicas e a necessidade de combater a penetração comunista no movimento sindical e nas Universidades. Representante do CIAS do Chile, Roger Vekemans recorda que "todos foram compreensivos com o padre visitador, mas ninguém caiu na armadilha de uma atitude negativa” (apud Beigel, 2011, p. 42, tradução nossa) ${ }^{8}$. Igualmente presente na reunião, o parecer de Carlos de la Torre Uribarren, diretor do CIAS de Torreón, do México (fundado, aliás, pelo próprio Foyaca em 1956), foi bem mais positivo: "As reuniões em Roma foram muito interessantes" . Deve ter contribuído para isso o fato de Carlos de la Torre ser mais próximo de algumas das concepções políticas de Foyaca. No caso do @ mexicano, por conta de sua participação, na juventude, antes mesmo de entrar na Companhia de Jesus, na Segunda Cristiada (1934-1938), ร quando se fez cristero, pegou em armas contra o governo, foi preso e quase fuzilado.

Não deve, portanto, causar espanto a combinação de (a) compromisso com a justiça

3ิ ${ }^{8}$ Não deixa de ser curiosa essa avaliação do padre Vekemans, o qual, uma década depois, no contexto da polarização ideológica chilena, se converteria num feroz anticomunista, acusado, inclusive, de receber financiamento da - Agência Central de Inteligência (CIA) norte-americana...

${ }^{9}$ Carta de Carlos de la Torre Uribarren para Xavier Enríquez. Torreón, 22 de dezembro de 1960, tradução nossa. Árquivo Histórico da Companhia de Jesus no México (AHCJM), Caixa CIAS, Pasta Correspondência de Carlos de la Torre Uribarren. social e (b) luta contra o comunismo, típica dessa primeira etapa dos CIAS. Na visita à Bolívia, em abril de 1962, uma das últimas realizadas por Manuel Foyaca como representante do Geral, ele se expressou nos seguintes termos:

O Padre Geral quer que intensifiquemos o apostolado social, cujo objetivo imediato é o desenvolvimento da ordem material e uma melhor repartição de riquezas, para que todos os povos da América Latina disfrutem ao menos de uma parcela substancial do bem-estar criado por Deus para toda a humanidade [...]. Por outro lado, esta situação de desequilíbrio e de miséria de grande parte das populações do continente proporciona a grande ocasião à Rússia, que deseja ir rapidamente à conquista do mundo, para uma grande ofensiva na América Latina. (Diáspora: Notícias de la Vice-Província Boliviana, La Paz, 30 de abril de 1962, p. 2, apud Klaiber, 2007, p. 284-285)

De fato, o período de montagem e articulação dos CIAS foi atravessado por inúmeras tensões e resistências. Em 1960, em plena vigência da Visita, Jean-Baptiste Janssens chegou a escrever uma carta aos Provinciais da América Latina exortando-os a examinar com seus consultores cada um dos aspectos da Instrução de 1949. Anexou um Memorial elaborado por Manuel Foyaca e deu um prazo de dois meses para que lhe mandassem de volta um informe sobre o progresso realizado (Diederich; Viscardi, 2001, p. 207). Dois anos depois, voltou a escrever aos Provinciais parabenizando-os pelos resultados obtidos e anunciando a nomeação de Manuel Foyaca como seu secretário para o Apostolado Social na América Latina. A Visita Social estava formalmente encerrada, o Secretariado Interamericano de Ação Social (SIAS) acabava de começar. Mas nem por isso os problemas de Foyaca haveriam de cessar...

\section{O SIAS E O CLACIAS}

Os últimos anos do generalato do padre Janssens foram bastante difíceis. Acometido de uma séria enfermidade ocular, que o deixou praticamente cego desde 1962, ele foi obrigado a nomear um Vigário Geral, o canadense John 
Swain, em abril de 1960, que o substituiu por alguns meses, tendo-o representado, inclusive, na primeira sessão do Concílio Vaticano II, em outubro de 1962. Apesar de prevista nas Constituições da Companhia de Jesus, tal situação não deixava de enfraquecer o governo da Ordem, mergulhada num permanente estado de expectativa. Falecido o Geral belga em 5 de outubro de 1964, os mais de trinta e seis mil companheiros dispersos pelo mundo inteiro tiveram ainda de aguardar até maio do ano seguinte, quando da abertura da Congregação Geral XXXI, para anunciar Habemus Prepositum!: o espanhol Pedro Arrupe y Gondra (aliás, o primeiro basco desde o fundador da Ordem, Inácio de Loyola, eleito mais de quatrocentos anos antes).

Assim, os primeiros anos do SIAS se deram em circunstâncias de relativa indefinição quanto aos rumos da Sociedade de Jesus. Instalado provisoriamente em Santo Domingo, na República Dominicana, para onde havia se transferido junto a uma dezena de jesuítas expulsos de Cuba, ao que parece Foyaca nunca obteve a confiança do novo Geral. Pelo menos é o que se deduz do entrecortado diálogo mantido entre eles, repleto de cartas nunca recebidas, respostas jamais enviadas etc., como podemos constatar nesta correspondência datada de novembro de 1965, poucos meses após a eleição de Arrupe:

Muy amado em Cristo Padre Geral. Em sua carta de 12 de setembro contestando a meu Informe de 27 de agosto, me dizia V. P. que aguardava sua resposta um pouco mais adiante, porém, esta carta nunca chegou a minhas mãos. Recebi, em troca, no dia 23 do atual, outra carta, datada do dia 9 e dirigida aos "Diretores dos CIAS da América Latina", incluindo um extenso questionário. Interpretando que não era apenas ad informationem, senão que lhe interessava meu parecer sobre o CIAS desta Vice-Província, enviei estas linhas respondendo às perguntas feitas no questionário. ${ }^{10}$

${ }^{10}$ Carta de Manuel Foyaca para Pedro Arrupe. Santo Domingo, 28 de novembro de 1965, p. 1, tradução nossa. Arquivo do Secretariado de Justiça Social (ASJS), Roma, Caixa CIAS.
Uma hipótese razoável é que Pedro Arrupe já houvesse tomado a decisão interior de reestruturar o apostolado social na América Latina, como que desconsiderando, em termos práticos, a mediação do SIAS, criado, como vimos, num momento delicado do generalato anterior. Daí porque preferia comunicar-se diretamente com os diretores de CIAS. Isso explicaria o fato de Foyaca não ser um interlocutor preferencial, na medida em que o CIAS de Cuba havia perdido sua efetividade com o triunfo da Revolução, e o das Antilhas lutava ferrenhamente para se consolidar, num contexto igualmente desafiador, posto que a longa ditadura de Rafael Leônidas Trujillo, encerrada com sua morte em maio de 1961, havia deflagrado uma guerra civil na qual os jesuítas terminaram se envolvendo (Cf. Sáez, 1988). Ademais, a figura jesuíta de proa no campo social dominicano era o padre Francisco José Arnaiz, vulgo Pepito, igualmente deportado de Cuba em 1961.

Não descartamos, porém, a possibilidade de uma divergência mais profunda entre ambos. A principiar pelo anticomunismo, que foi se tornando um traço cada vez mais entranhado na personalidade e na conduta de Manuel Foyaca, e que, em contraposição, consistia num dos componentes ideológicos menos apreciados por Pedro Arrupe, como o demonstrou à exaustão seus quase vinte anos de generalato. E não resta dúvida de que eles se conheciam muito bem, já que o basco Arrupe, apenas dois anos mais jovem que Foyaca, pertencia à Província de Castela e também foi obrigado a concluir seus estudos fora da Espanha quando do advento da Segunda República. Para onde ele foi destinado? Justamente para Marneffe, na Bélgica, no mesmo período (entre 1932 e 1933) em que o cubano concluía seu curso de Filosofia.

O certo é que o exílio dominicano de Foyaca foi uma temporada de crescente perda de autoridade e influência. Ele próprio reconheceu isso quando, nessa mesma missiva de novembro de 1965, queixou-se ao Geral acerca dos infortúnios enfrentados para a estabiliza- 
ção do SIAS. Segundo ele, o padre Janssens e o Vice-Provincial das Antilhas haviam concordado previamente com a constituição do Secretariado Interamericano em Porto Rico, com o apoio da Província de Nova York, dadas as dificuldades políticas e econômicas da República Dominicana, o que acabou sendo descumprido. Como se não bastasse, o novo Vice-Provincial das Antilhas não aceitou a integração do SIAS na estrutura do CIAS local, rompendo ao mesmo tempo, de fato, todo nexo entre ambos os organismos. O ostracismo a que foi relegado Foyaca é primorosamente ilustrado pelo episódio narrado por seu conterrâneo, o jesuíta Román Espadas, que, ao encontrá-lo em meados da década de 1960 numa residência da Companhia de Jesus em Santo Domingo, perguntou-lhe: "O que você anda fazendo?" Ao que Foyaca respondeu: "Estou escrevendo cartas para meus amigos". ${ }^{11}$

A reestruturação, enfim, aconteceu. $\mathrm{O}$ CLACIAS (Conselho Latino-Americano dos CIAS) foi criado em 12 de dezembro de 1966 para coordenar os onze Centros de Investigação e Ação Social então existentes na América Latina (Antilhas, Argentina, Bolívia, Brasil, Chile, Colômbia, Equador, México, Paraguai, Peru e Uruguai). A decisão havia sido tomada meses antes, na reunião plenária dos CIAS latino-americanos ocorrida em Lima (Peru), entre . 25 e 29 de julho de 1966. Em correspondência $\stackrel{\sim}{:}$ enviada aos demais diretores, provavelmente $\circlearrowleft$ seu último ato à frente do SIAS, Manuel FoyaI ca esclarecia que o tema central, “que disporá $\rightarrow$ do tempo necessário para seu completo estuஜ do, é a estrutura, objetivos e inter-relação dos 될 CIAS”"12. Com mais de trinta jesuítas presentes, $\dot{*}$ o lugar de destaque da reunião coube à deleจิ gação do Centro Bellarmino, do Chile, integra$>$ da pelos padres Pierre Bigo, Hernán Larraín, Roger Vekemans e Gonzalo Arroyo. O Geral de 2015. Agradeço igualmente a generosa acolhida do padre Román em Cuba, bem como sua inestimável colaboração na

${ }^{12}$ Carta-circular de Manuel Foyaca. Roma, 15 de junho de 1966, tradução nossa. Arquivo do Secretariado de Justiça Social (ASJS), Roma, Caixa CIAS.
Pedro Arrupe não participou pessoalmente do encontro, fazendo-se representar por três membros da Cúria Geral. Mas enviou uma carta a todos Superiores da Companhia de Jesus anunciando as mudanças:

Formado por vários Coordenadores Regionais e um Secretário Executivo, este novo órgão [o CLACIAS] desempenhará oficialmente a função de informação e correspondente consulta técnica aos Provinciais, à consulta técnica do Padre Geral e ao próprio Padre Geral. ${ }^{13}$

Em sua primeira fase, o CLACIAS foi sediado em Santiago (Chile), no mesmo prédio do recém-fundado Instituto Latinoamericano de Doctrina y Estudios Sociales (Ilades), e teve como primeiros secretários-executivos, nomeados pelo Padre Geral, exatamente dois jesuítas do Centro Bellarmino: de dezembro de 1966 a fevereiro de 1968, o chileno Hernán Larraín, substituído, por problemas de saúde, pelo francês Pierre Bigo, que exerceu o cargo até 1972. A escolha da sede e da direção não teve nada de fortuita. Doravante, o apostolado social da Companhia de Jesus tenderia a se profissionalizar cada vez mais, investindo na constituição de centros de produção intelectual ligados às questões sociais, sem, com isso, afrouxar os vínculos com os episcopados católicos nacionais e as redes humanitárias de ativismo transnacional em defesa dos direitos humanos (Cf. Beigel, 2011; Catoggio, 2014).

A América do Sul ocupará um espaço privilegiado nessa nova dinâmica, com destaque para a tríade formada por Ilades, Instituto de Doctrina y Estudios Sociales (Ides) e Instituto Brasileiro de Desenvolvimento (Ibrades). A começar pelo chileno Ilades, fundado em 1965 por iniciativa do cardeal arcebispo de Santiago, Raúl Silva Henríquez, e do bispo de Talca, Manuel Larraín, como uma instituição destinada à investigação e à docência, com a finalidade de difundir a Doutrina Social da Igreja e formar dirigentes cristãos, tendo como paradigma a parisiense $A c$ -

${ }^{13}$ Carta de Pedro Arrupe a los Superiores Mayores de América Latina. Roma, 12 de dezembro de 1966, p. 1, tradução nossa. Arquivo do Centro de Documentacão do Centro de Estudos e Ação Social/Casa da Memória Popular (Campo), Salvador, Fundo Companhia de Jesus, Pasta CIAS. 
tion Populaire. (Fernández, 2013). Seus congêneres, colombiano e brasileiro, foram criados no mesmo ano, 1968: o Ides, pela CEC (Conferência Episcopal Colombiana), e logo confiado ao CIAS Colômbia, de Bogotá; o Ibrades, pela Conferência Nacional dos Bispos do Brasil (CNBB), e administrado desde os primórdios pelo CIAS João XXIII, do Rio de Janeiro. A Companhia de Jesus reforçava, assim, sua posição hegemônica na rede de cooperação internacional católica, para bem melhor "amar e servir" (Loyola, 1928, EE. 233). Mas essa já é outra história.

Recebido para publicação em 15 de outubro de 2015 Aceito em 21 de novembro de 2015

\section{REFERÊNCIAS}

ABREU, A. J. M. de. O diálogo do pensamento cristão com o mundo (entrevista). IHU On-Line, n. 337. São Leopoldo: Unisinos, 2 ago. 2010.

AIXALÁ, J. Visitador. In: O'NEILL, C. E.; DOMINGUEZ, J. M. (org.). Diccionario Histórico de la Compañía de Jesús. Tomo II. Roma: Institutum Historicum Societatis Iesu; Madri: Universidad Pontificia Comillas, p. 1748-1749, 2001.

ANTONCICH, R. Apostolado Social: sector y dimensión apostólica. Rio de Janeiro: Conferência dos Provinciais Jesuítas da América Latina, s. d.

BEIGEL, F. Misión Santiago: el mundo académico jesuita y los inicios de la cooperación internacional católica. Santiago: LOM, 2011.

CALVEZ, Jean-Yves. Marxismo. In: O'NEILL, C. E.; DOMINGUEZ, J. M. (org.). Diccionario Histórico de la Compañía de Jesús. Tomo II. Roma: Institutum Historicum Societatis Iesu; Madri: Universidad Pontificia Comillas, p. 1457-1459, 2001.

CAMACHO, I. Doutrina Social da Igreja: abordagem histórica. São Paulo: Loyola, 1995.

CARTER, M. El papel da la Iglesia en la caída de Stroessner. Assunção: RP Ediciones, p. 82-88, 1991.

CATOGGIO, María Soledad. La trama religiosa de las redes humanitarias y el activismo transnacional en las dictaduras del Cono Sur de América Latina. In: JENSEN. Silvina; LASTRA, Soledad. Exilios: militancia y represión. Nuevas fuentes y nuevos abordajes de los destierros de la Argentina de los años setenta. La Plata: Universidad Nacional de La Plata, 2014.

COSTA, I. S. Os Confessores de Marx: a Companhia de Jesus e o Marxismo (1937-1982). Revista de História, n. 162 São Paulo: Universidade de São Paulo, p. 335-368, 2010.

Que papo é esse? Igreja católica, movimentos populares e política no Brasil (1974-1985). Feira de Santana (BA): UEFS, 2011.

CZERNY, M.; FOGLIZZO, P. El Apostolado Social en el siglo XX. Promotio Iustitiae, n. 73. Roma: Secretariado de Justiça Social da Companhia de Jesus, p, 7-17, mai. 2000.

DIEDERICH, E.; VISCARDI, C. Acción Social Jesuita. In: O’NEILL, C. E.; DOMINGUEZ, J. M. (org.). Diccionario
Histórico de la Compañía de Jesús. Tomo I. Roma: Institutum Historicum Societatis Iesu; Madri: Universidad Pontificia Comillas, p. 205-208, 2001

DINGER, J. Os anos do Condor: uma década de terrorismo internacional no Cone Sul. São Paulo: Companhia das Letras, 2005.

DROULERS, P. Le père Desbuquois et l'Action Populaire. 2 Volumes. Paris: Ouvrières; Roma: Pontifícia Universidade Gregoriana, 1981

ESTUDIOS CENTROAMERICANOS (ECA). Para onde vai a Igreja? Cadernos do CEAS, n. 99. Salvador: CEAS, p. 5158, set./out. 1985

FERNÁNDEZ, F L. Ilades: testimonio de una historia, 1965-1998. Santiago: Universidade Alberto Hurtado, 2013.

FOYACA, M. Instrução do Padre Manuel Foyaca. In: COMPANHIA DE JESUS. Pastoral Popular: fundamentação inaciana. São Paulo: Loyola, p. 115-142, 1991.

HURTADO, A. Cartas e Informes del Padre Alberto Hurtado. 3. ed. Santiago: Universidad Católica de Chile, 2005.

JANSSENS, Jean-Baptiste. Instrução sobre o Apostolado Social. Roma, 10 de outubro de 1949. In: COMPANHIA DE JESUS. Pastoral Popular: fundamentação inaciana. São Paulo: Loyola, p. 85-113, 1991

KLAIBER, J. Los jesuitas en América Latina, 1549-2000: 450 años de inculturación, defensa de los derechos humanos y testemonio profético. Lima: Universidad Antonio Ruiz de Montoya, 2007.

LAVÍN, A.; HOLLEY, M.; LARRAÍN, M. Biografía y testimonios del Padre Alberto Hurtado. Santiago: Centro de Estudios y Documentación Padre Hurtado de la Pontificia Universidad Católica de Chile, 2005.

LÖWY, M. A guerra dos deuses: religião e política na América Latina. Petrópolis: Vozes; Rio de Janeiro: LPP UERJ; Buenos Aires: CLACSO, 2000.

LOYOLA, I. de. Exercitia Spiritualia Sancti Patris Ignatii de Loyola. Versio litteralis. Ejercicios Espirituales de San Ignacio de Loyola. Texto Castellano. Roma: Marietti, 1928.

Carta de Santo Inácio aos Padres e Irmãos de Pádua. Roma, 6 de agosto de 1547. In: COMPANHIA DE JESUS. Pastoral Popular: fundamentação inaciana. São Paulo: Loyola, p. 77-84, 1991.

MENESES, P. Os CIAS na América Latina e no Brasil. In: SCHÜHLY, Günther; KÖNIG, Hans-Joachim; SCHNEIDER, José Odelso (org.). Consciência social: a história de um processo através da Doutrina Social da Igreja. São Leopoldo: Unisinos, p. 273-280, 1994.

MORELLO, G. Perfil e historia del CIAS. CIAS, v. XLIX, n. 490, p. 47-55. Buenos Aires: CIAS, mar. 2000.

O NEOLIBERALISMO NA AMÉRICA LATINA. Carta dos Superiores Provinciais da Companhia de Jesus da América Latina (documento de trabalho). São Paulo: Loyola, 1996.

O PRIMEIRO ENCONTRO LATINO-AMERICANO DE CRISTÃOS PARA O SOCIALISMO. Cadernos do CEAS, $\mathrm{n}$. 24, p. 36-46. Salvador: CEAS, abr. 1973.

RIERA, I. Qué son los CIAS. In: La Carta del Padre Arrupe: requiem por el Constantinismo. Barcelona: Nova Terra, $\mathrm{p}$. 27-28, 1968

SÁEZ, J. L. Los jesuitas en la Republica Dominicana. 2 Volumes, Santo Domingo: Museu Nacional de História e Geografia; Arquivo Histórico das Antilhas, 1988.

SEGUNDO, J. L. Livres e responsáveis: o legado teológico de Juan Luís Segundo. Entrevista a Jesús Castillo Coronado. São Paulo: Paulinas, (p. 48-56), 1998.

SERBIN, K. P. Diálogos na sombra: bispos e militares, tortura e justiça social na ditadura. São Paulo: Companhia das Letras, 2001. 


\section{TO LOVE AND TO SERVE IN THE SOUTH OF AMERICA: origins and articulations of the Jesuit social centers}

\author{
Iraneidson Santos Costa
}

Since Ignatius of Loyola's Letter to the Fathers and Brothers at Padua, 1547, the Social Apostolate has been one of the central dimensions of charism in the Society of Jesus. However, this gained a higher profile during the creation of the so-called Centers of Research and Social Action (CIAS) in several South American countries between 1950 and 1970. Based on documentation originating from various files from the Society of Jesus in Brazil, Italy, Mexico and Paraguay, we will discuss the origins and articulations of South American CIAS, initially through the Inter-Secretariat for Social Action (SIAS), and then through the Latin American Council of CIAS (CLACIAS), by inserting them in a context marked by ideological and political biases. Throughout the article, we try to show the central hypothesis of our research: the trajectory of CIAS is marked by constant tension between two opposing forces: (a) the commitment to social justice and (b) the fight against communism.

Keywords: Society of Jesus. CIAS. Social Justice. Liberation theology. South America.

\section{AIMER ET SERVIR EN AMÉRIQUE DU SUD: l'origine et l'articulation des centres sociaux jésuites}

\author{
Iraneidson Santos Costa
}

Depuis la lettre d'Ignace de Loyola aux Pères et aux Frères de Padoue en 1547, l'Apostolat Social est l'une des dimension centrale du charisme de la Compagnie de Jésus. Un tel choix a cependant acquis une nouvelle dimension lors de la création de ce que l'on a appelé les Centres de Recherche et d'Action Sociale (CIAS) dans plusieurs pays d'Amérique du Sud entre les années 1950 et 1970. En nous basant sur la documentation issue des archives de la Compagnie de Jésus au Brésil, en Italie, au Mexique et au Paraguay, nous analysons l'origine et les liens qu'ont entre eux les CIAS sud-américains, tout d'abord par l'intermédiaire du Secrétariat Inter-américain d'Action Sociale (SIAS), suivi immédiatement du Conseil Latino-américain des CIAS (CLACIAS), en les insérant dans un contexte très marqué par des polarisations idéologiques et politiques. Tout au long de l'article nous essayons de faire une démonstration de l'hypothèse centrale de notre recherche : la trajectoire des CIAS a été marquée par une tension permanente entre deux forces opposées, (a) l'engagement envers la justice sociale et (b) la lutte contre le communisme.

Mot-CLÉs: Compagnie de Jésus. CIAS. Justice sociale. Christianisme de Libération. Amérique du Sud.

Iraneidson Santos Costa - Doutor em História. Professor do departamento de História e do Programa de Pós-Graduação em História (UFBA). Tem experiência nas áreas de História e Sociologia. Tem realizado pesquisas na área de Religião, Política e Movimentos Sociais na América Latina e no Nordeste brasileiro e desenvolvido atividades de Extensão no campo da História e Memória das Lutas Populares na Bahia. Publicações recentes Os Bispos Nordestinos e a criação da CNBB. Interações: Cultura e Comunidade (Uberlândia. Online), v. 9, p. 109-143, 2014; Eu ouvi os clamores do meu povo': o episcopado profético do Nordeste brasileiro (I have heard the cries of my people-: prophetic bishops of Brazilian northeast) DOI: 10.5752/P.2175-5841.2013v11n32p1461. Horizonte: Revista de Estudos de Teologia e Ciências da Religião (Online), v. 11, p. 1461-1484, 2013; A eficácia de uma presença libertadora: a trajetória do padre Cláudio Perani (1932-2008). Revista Perspectiva Histórica, v. 1, p. 47-56, 2011. 